\title{
URBAN SPRAWL AND MOBILITY
}

\author{
GIUSEPPE GALIANO ${ }^{1}$, GIULIA FORESTIERI ${ }^{2} \&$ LAURA MORETTI $^{1}$ \\ ${ }^{1}$ Department of Civil, Constructional and Environmental Engineering, Sapienza University of Rome, Italy \\ ${ }^{2}$ Facultad de Ingeniería, Universidad de La Sabana, Campus universitario del Puente del Común, \\ km.7 Autopista norte Bogotá,Chía, Cundinamarca, Colombia
}

\begin{abstract}
In the last century the territory and the layout of the cities have undergone important changes with an enlargement in the space of human settlements. It deserves attention in terms of the principles of sustainability, limitation of soil consumption, environmental impacts and social needs. Then, a holistic vision for the definition of city and its mobility is needed. This paper introduces a systemic conceptual framework for the urban planning by combining different definitions and illustrating a review of the main themes of modern urban planning. This study analyzes the relationship between urban sprawl and upward mobility. Territorial dynamics, transport issues, and effects of the urban decentralization are examined. Moreover, the TOD (transit oriented development), based principally on the presence of central transport stops in a medium-high density area, and the smart growth models, focusing on a compact city improving sustainable transports like pedestrian mobility and bicycles, are also illustrated. The analyzed criteria for city management and organization could be applied to the present emergency due to COVID-19 and its new challenges. The recent pandemic has highlighted the need to reorganize and adapt public services to obtain self-sufficient neighborhoods, where short distances are preferred and mobility is limited: $f$ smart cities, defined as compact and green, could answer COVID-19 related necessities.
\end{abstract}

Keywords: urban planning, sprawl, smart growth, sustainability, mobility, COVID-19.

\section{INTRODUCTION}

Urban areas continue to grow rapidly and provoke urban environmental problems that affect the quality of life of citizens. The discussion is so vivid that politicians are aware that sustainable urban growth management and environmental sustainability in megacities of developing countries are urgent according to the Millennium Development Goals "MDG" [1]. Under such context, transportation plays an important role for the economic development of cities and for the social and economic wellbeing of their inhabitants. The relationship between land and transportation is seen as a contrasting and irremediable duality. For one hand, many authors affirm that those categories are distant, while. Other authors argue that the increase in mobility and technological innovation has produced significant and visible changes in the cities structures [2]. Those modifications have remained etched in the urban fabric as traces of the different transitions from one mode of transport to another: from animal traction to mass motorization of the 1950s; from the introduction of public and rail transport to modern sustainable mobility trends. In this trend, the revamped electrification of public transport [3] is an attempt to reconcile mass transit demand with environmental concerns and built environments safeguard [4]. However, among transportation implications in the urban asset, car is the main character. It has revolutionized the choices regarding the location of residential and production activities and structures, modifying habits and lifestyles. Vehicles have shortened distances making people free and autonomous in their travels. After the 19th century, popularity of cars became an important force driving the spread of cities, and cities gradually lost their compact form. Dependence on cars has led, on the other hand, the territory to a form of extreme dispersion with several problems related to traffic congestion: the widespread city [5] and its externalities affect the whole world. The central urban area declined, the urban and suburban land use were one of the main phenomena of urban 
decentralization [6]. Over the last century substantial changes in urban spatial structure have taken place in worldwide cities, which attracted increasing attention from geographers, economists, sociologists, and urban planners [7], [8]. They have carried out analytical efforts aimed at defining the new paradigms of urban form and evolution as follows:

- global city [9]: the globalization of the economy, associated with the emergence of a global culture, has altered social, political and economic reality of large transnational areas and cities. The emerging globalization of economic activities lead to believe that cities are not as important as in the past;

- sprawltown [10]: this word borne from urban problems such as city escape, out-ofcontrol suburban development, and the transformation of rural soils into residential settlements;

- widespread city [11]: there is a widespread city whenever, even in the absence of physical proximity, conditions of urban use of the territory occur. It is an urban phenomenon not from a morphological point of view, but for its organizational, functional, social and use elements; and

- infinite city [12]: it is a "not place," but as an infinite succession of places that appear to travelers passing through them.

However, the population redistribution among large cities and small towns is not the only transformation taking place, since decentralization affects both residential functions and productive activities. According to Garreau [13] the decentralization of jobs and people to the outside of a city's traditional center is also known as "nucleated dispersion," especially for U.S. cities, that helps form new suburban centers and thus facilitates the emergence of polycentric metropolises. The decentralization of the city's productivity has been influenced by market forces and government interventions [14], [15]. Productivity's decentralization has a direct impact on urban mobility: people moving every day from suburbs to central areas and vice versa increases the traffic congestion. Urban dispersion is accompanied by a "mobility basins" expansion connected to home-work journeys [16]. Indeed, sprawl is strictly related to mobility in terms of commute times to work [17]. This is principally due to the long-distance travel among main services that discourage pedestrian or bicycle travel. Moreover, there is almost often no efficient public transport network for the low urban density in the suburbs which would make the realization of a transportation network too expensive. Therefore, urban growth management designed to curb urban sprawl is necessary to contain the need for long-distance travel and car use for such trips [18]. Reducing travel time could improve the proximity of the region and promote knowledge dissemination [19].

The on-going pandemic of coronavirus disease 2019 has amplified the decentralization, started since approximately twenty years ago [20] in part due to the smart working that helps change the socio-economic dynamics. Therefore, sustainable transportation, which is characterized by shorter trips' length and time, less reliance on the car and more efficient public transport, is a key issue for sustainable urban growth. This paper aims to investigate the relationship between land use and transportation in order to understand how spatial distribution of activities and mobility influence each other. In the past decades, several models to counter urban dispersion have been defined, but rarely put into practice. Today it is necessary to implement these proposals to give an answer to the issues related to the COVID-19 pandemic which urges redaction in mobility.

\section{EFFECT OF SPRAWL ON URBAN TRANSPORT}

The consequences of urban dynamics on mobility are numerous and complex. Many authors have explored this theme and highlighted the following issues: 
- Number of vehicle kilometers travelled: there is a strong correlation between urban dispersion and vehicle kilometers travelled on daily journeys. The decentralization of productive and residential destinations throughout the territory and socio-demographic factors have led to an increase in the distances travelled with consequent economic and emissions costs [21], [22].

- Travel time: the proximity among public services would help to decrease long-distance travel. Urban growth management designed to curb urban sprawl on fringe areas could contain the need for long-distance travel and car use for such trips. In fact, the potential contribution of urban growth management to the reduction of the environmental effects of transport has been empirically proven in Western cities [7].

- Modal choice: pedestrian and light mobility, typical of compact cities, might help to reduce the use of private cars and its impact [23]. Transport infrastructures should answer to the increasing modal shift from public mass transport to both motor-vehicle private transport and light vehicles (e.g., bikes, push scooters). Therefore, the transport infrastructures layout should be modified to ensure safe movements to vulnerable users [24].

- Transport costs: compact cities help to reduce transport costs improving public transport [25] and pedestrian mobility [26]. Furthermore, private transport costs have recently increased in relation to the Coronavirus disease 19 (COVID-19) pandemic, which has led to the greater use of private vehicles due to the fear of contagion on public transport.

- Transport externalities: by contributing to the increase in traffic on the roads, urban dispersion would seem to aggravate the external costs of mobility (e.g., air pollution, noise emission, road accidents, depletion of abiotic resources, deterioration of the environment and the ecosystem [27]-[29].

- Car dependence (Fig. 1): it is both a strong limit to the achievement of sustainable mobility goals and an indicator of social inequality. Where public transport services are absent or inefficient, private cars represent the only way of transport [30]. Furthermore, inconveniences increase for minors or people with disabilities.

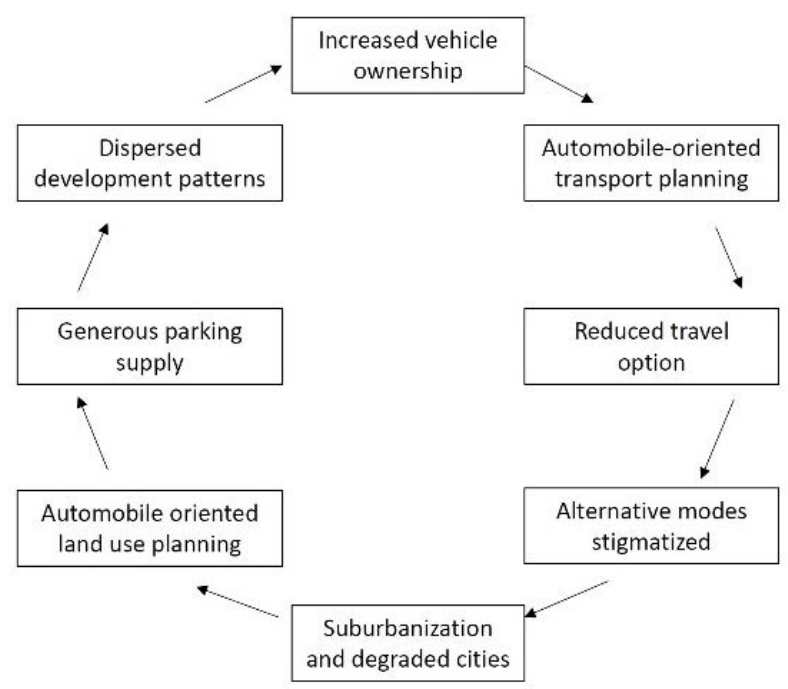

Figure 1: Cycle of automobile dependency [31], [32]. 
3 TOD

The acronym TOD identifies "transit-oriented development" [33], a planning concept that differs from the conventional sprawl development. Urban and transportation planners have different understanding of TOD. Bernick and Cervero [34] define TOD as a compact and mixed-use neighborhood arranged around a transit station site as a hub connecting the neighborhood with other areas. Its surrounding public space plays an important role as the center of the neighborhood and meeting place of the area. Still [35] affirms that TOD represents a mixed-purpose neighborhood which encourages people to live near transit services in order to reduce car dependence. According to Cervero et al. [36], TOD refers to mixed-use land development, proximity of transit services, and favor of transit development and to mix of residence, employment, commercial, and public services, with a large bus or rail transit station within a walkable range.

Among different TOD definitions [37], main common factors can be identified:

- functional mix;

- development in surrounding areas served by local public transport;

- development that increases the use of collective methods;

- compactness;

- pedestrians and bicycles paths;

- $\quad$ public spaces and services adjacent to the stations; and

- stations intended as community and transportation hubs.

The TOD concept has been widely promoted and practiced from the 1990s and graphically represented in the scheme elaborated by Calthorpe [37], who lays the foundations for a new city conception (Fig. 2).

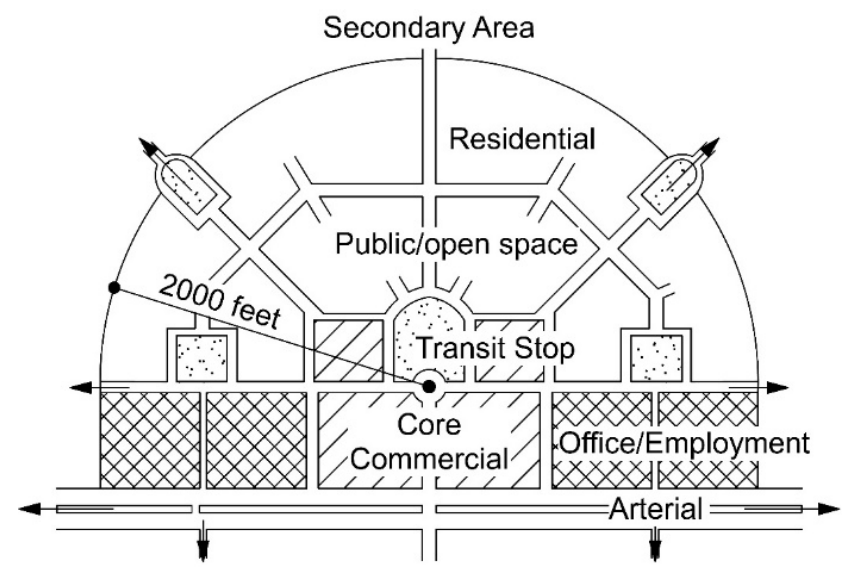

Figure 2: TOD city scheme [37].

According to Fig. 2, density represents the key factor of the Calthorpe TOD model in order to arrange city functions around an efficient transport network. Dispersed suburbs with a very low density are not included inside that model. Indeed, groups of residential uses and services around public service stops help to increase suburbs density with a radial concentration where the central part is represented by the core commercial directly connected 
to the transit stop and the external ones by residential areas. The radial urban form is developed taking into account distances that can be covered by foot from public transport stops. The development of larger commercial core areas and office space are encouraged in the central part, while neighborhood emphasizes a higher proportion of residential development in the external areas based on the necessary commercial core areas [33]. TOD impacts on car dependence vary according to the social distribution. Where the possession and use of private vehicles is limited due to a predominance of lower, middle-class people, people are encouraged to live close to transport stops increasing accessibility, and the outcome will be modest. On the other hand, if TOD is applied in a social context where people make a strong use of the car, the model has greater possibilities to reduce the use of private cars (and kilometers travelled). In some cases, increasing accessibility and reducing kilometers travelled are favored when residential areas and workplaces are close, while in other ones they are not favored because of the factors described below:

- where road congestion occurs, accessibility is reduced due to the speed reduction, while the kilometers travelled decrease as the number of journeys is limited;

- lack of urban policies encouraging facilities to access cars at affordable prices; and

- areas characterized by low density and propensity to use private vehicles result in an increase in kilometers travelled and a decrease in accessibility.

The preservation of the natural environment and the architectural heritage [38], [39] is included in the TOD model as large green bands among the areas of urban growth are respected. Moreover, the modular radial urban structure does not prejudice the possibility of further expansion since free areas are devoid of widespread low-density settlements. An urban reorganization of decentralized areas according to the TOD principles, principally based on the transport network, should be encouraged in order to prioritize environmental and sustainability issues in the actual urban planning.

\section{SMART GROWTH}

Smart cities are a common concept for science and policy to promote urban sustainable development even though its concept is not well-defined [40] since distinct perspectives are included: communication and information technologies as part of a smart economy; human capital as smart people; e-governance or e-democracy as smart governance [41].

Smart growth describes in a wider sense, on one hand, an economic development path balancing growth with a careful use of natural resources and social inclusion of urban residents [42] and on the other, those policies aimed at integrating transport and land use. This last aspect aims at favoring compact development and functional rebalancing, and at the same time discouraging dispersed and car-dependent urban growth, the opposite urban scheme to sprawl [32].

Among them, it can be noticed that smart growth is centered on the neighborhood conceived as village, an area of limited extension (from $400 \mathrm{~m}$ to approximately $1 \mathrm{~km}$ in diameter) with public services and shops nearby the central area. Thereby, smart growth is often used synonymously with compact cities [43] opposed to sprawl city where mobility is one of the main characteristics [44] (Table 1).

Strategies for obtaining a smart growth are many ranging from: the environment considered as essential for securing sustainable growth and limiting urban sprawl [41]; high physical density of residential and commercial areas promoting space-efficient urban forms and vertically developed building instead of horizontal, low-density developments common 
Table 1: Differences between sprawl growth and sprawl [48].

\begin{tabular}{|c|c|c|}
\hline & Smart growth & Sprawl \\
\hline Growth pattern & $\begin{array}{l}\text { Mostly infill (brownfield) } \\
\text { development }\end{array}$ & $\begin{array}{l}\text { Mostly urban fringe (greenfield) } \\
\text { development }\end{array}$ \\
\hline Density & $\begin{array}{l}\text { Higher-density, clustered } \\
\text { activities }\end{array}$ & $\begin{array}{l}\text { Lower-density, dispersed } \\
\text { activities }\end{array}$ \\
\hline Land use mix & Mixed land use & $\begin{array}{l}\text { Homogeneous (single-use, } \\
\text { segregated) land uses }\end{array}$ \\
\hline Scale & $\begin{array}{l}\text { Human scale. Smaller blocks and } \\
\text { roads, more local services, for } \\
\text { pedestrian access }\end{array}$ & $\begin{array}{l}\text { Large scale. Larger blocks, } \\
\text { wider roads, more regional } \\
\text { services, assuming automobile } \\
\text { access }\end{array}$ \\
\hline $\begin{array}{l}\text { Services (shops, } \\
\text { schools, parks) }\end{array}$ & $\begin{array}{l}\text { Local, distributed, smaller. } \\
\text { Accommodates walking access }\end{array}$ & $\begin{array}{l}\text { Regional, consolidated, larger. } \\
\text { Requires automobile access }\end{array}$ \\
\hline Housing types & $\begin{array}{l}\text { Diverse, including compact } \\
\text { housing types such as townhouses } \\
\text { and apartments }\end{array}$ & Single-family housing \\
\hline Transport & $\begin{array}{l}\text { Multi-modal. Supports walking, } \\
\text { cycling and public transit }\end{array}$ & $\begin{array}{l}\text { Automobile-oriented. Poorly } \\
\text { suited for walking, cycling and } \\
\text { transit }\end{array}$ \\
\hline $\begin{array}{l}\text { Transport } \\
\text { connectivity }\end{array}$ & $\begin{array}{l}\text { Highly connected roads, } \\
\text { sidewalks and paths, and good } \\
\text { connections between modes }\end{array}$ & $\begin{array}{l}\text { Poorly connected networks, } \\
\text { with numerous dead-end streets, } \\
\text { few paths, and inadequate } \\
\text { connections between modes }\end{array}$ \\
\hline Parking supply & $\begin{array}{l}\text { Lower parking supply, higher } \\
\text { parking prices }\end{array}$ & $\begin{array}{l}\text { Parking facilities are abundant } \\
\text { and usually unpriced }\end{array}$ \\
\hline Street design & $\begin{array}{l}\text { Complete streets that } \\
\text { accommodate diverse modes and } \\
\text { activities }\end{array}$ & $\begin{array}{l}\text { Streets designed to maximize } \\
\text { motor vehicle traffic volume } \\
\text { and speed }\end{array}$ \\
\hline $\begin{array}{l}\text { Planning } \\
\text { process }\end{array}$ & $\begin{array}{l}\text { Planned and coordinated between } \\
\text { jurisdictions and stakeholders }\end{array}$ & $\begin{array}{l}\text { Poorly planned, with little } \\
\text { coordination between } \\
\text { jurisdictions and stakeholders }\end{array}$ \\
\hline Public space & $\begin{array}{l}\text { Emphasis on the public realm } \\
\text { (streets, sidewalks and public } \\
\text { parks) }\end{array}$ & $\begin{array}{l}\text { Emphasis on the private realm } \\
\text { (yards, shopping malls, gated } \\
\text { communities, private clubs) }\end{array}$ \\
\hline
\end{tabular}

in sprawl cities [45]; high quality of urban green spaces in the built environment to improve the quality of compact and green cities [41]; proximity among city areas, especially to green spaces and short distances to maximize the urban green ecosystem benefits [46]; multifunctional mix of uses promoting proximity to working, shopping and recreation; social aspects like densification and greening for the promotion of health benefits for urban residents [47].

\section{COVID-19 AND THE NEW NEED OF COMPACT URBAN AGGREGATES}

The COVID-19 pandemic has rapidly showed complex scenarios for city structure and organization. Strict restrictions on travel and individual mobility of citizens have been adopted to contain the spread of severe acute respiratory syndrome coronavirus 2 (SARS- 
CoV-2) [49] because such interventions demonstrated their positive effects in China [50]. Distances between people are increasing, in contrast to the consolidated tendency to shortening spaces and times, and the neighborhood relationship is assuming a central role because it represents the only admitted one during this crisis period. Pedestrian mobility and shopping activities nearby play a pivotal role that requires new approaches to urban planning, transport infrastructures and buildings.

The direct effects of the pandemic hit hard the transportation sector: the demand volume decreased and the modal choices changed and they will change until the end of the emergency [51]. Particularly, the most relevant modifications due to physical distance measures and modification of daily routine are:

- traffic flows reduced by up to $90 \%$ in the severely affected cities [52];

- $\quad$ reduction in average mobility (based on distance travelled) [53]; and

- $\quad$ significant modal shift from public mass transport to private transport [54].

Therefore, the new scenario will imply changes that affect transport infrastructures in the urban built environment, such as:

- Private transport in urban environment will increase the demand of transport by car and not-motor vehicles, as light vehicles (e.g., bikes, push scooters) that requires modification of the current infrastructures layout in order to ensure safe movements to vulnerable users [55].

- Reduction of travelled distances will increase the pedestrian movements: sidewalks and shared areas where different transport modes interact will be more used to serve the neighborhood relationships [56], [57]. Pedestrians walk where they feel comfortable or attracted, so design and maintenance of sidewalks and shared areas should prevent filthy, distressed or too narrow surfaces that induce users to jaywalk or walk on the carriageways [58], [59].

\section{CONCLUSIONS}

Due to the ongoing disintegration forces, territory is transformed into a low-density urbanized space where disadvantages coming from the city (traffic and pollution) and from the suburbs (automobile dependency, long travel distances, lack of services) are combined. Private cars have become the principal transport mode. In recent years, in the literature, several studies on the correlation between urban planning and transport identified the most sustainable strategies.

This paper deepens two urban models that are currently implemented in sustainable urban regeneration projects. The TOD model, on one hand, proposes the realization of a mixed area with residential and commercial services provided by central transport stops helping the internal mobility. For what concerning the density of the urban areas, it decreases from the central point as a medium-high density to the surrounding area into a low one. The smart growth model, on the other hand, proposes a compact, pedestrian city that increases sustainable ways of transport such as bicycles use. Moreover, neighborhood schools, roads with mixed permeability and areas with many services are included.

Therefore, both models could contribute to change physical and administrative assets of territories as required by the COVID-19 emergency. Researchers and urban planners are confronted to approach different definitions of cities, mobility and the new challenges caused by the pandemic. 
This paper contributes to a better understanding on how compact and green cities can be advanced exploring a review of the main themes of urban planning. In contrast to the ongoing worldwide uncontrolled expansion of urban development resulting in sprawled cities, smart cities represent a sustainable urban form. Indeed, design of sustainable cities has been widely theorized over the years in order to obtain a polycentrism widespread. From an urbanistic point of view, the Coronavirus disease could make a radical change on urban layout that allows new level of health in the city. In these way small cities, districts and neighborhoods will catch a level of autonomy with respect to the rest of the territory, according to the development of a sustainable transport network.

\section{REFERENCES}

[1] Zhao, P., Sustainable urban expansion and transportation in a growing megacity: Consequences of urban sprawl for mobility on the urban fringe of Beijing. Habitat International, 34(2), pp. 236-243, 2010.

[2] Larsen, K. \& Höjer, M., Technological innovation and transformation perspectives in environmental futures studies for transport and mobility. International Journal of Foresight and Innovation Policy, 3(1), pp. 95-115, 2007.

[3] Bousse, Y., Corazza, M.V., Sessing, G. \& Salzillo Arriaga, D., Electrification of public transport in Europe: Vision and practice from the ELIPTIC project. IEEE Xplore, Oct. 2018. DOI: 10.1109/EEEIC.2018.8494518.

[4] Corazza, M.V., Imbastaro, S. \& Pascucci, M., Regenerating communities. New life for a local railway: A technological and environmental study. Sustainability, 12, p. 3693, 2020. DOI: 10.3390/su12093693.

[5] Indovina, F., Matassoni, F., Savino, M., Sernini, M., Torres, M. \& Vettoretto, L., La città diffusa, STRATEMA, Laboratorio di Strategie Territoriali, DAEST: Venice, Italy, 1990.

[6] Audirac, I., Information technology and urban form: Challenges to smart growth. International Regional Science Review, 28(2), pp. 119-145, 2005.

[7] Li, Y., Towards concentration and decentralization: The evolution of urban spatial structure of Chinese cities, 2001-2016. Computers, Environment and Urban Systems, 80, 2020. DOI: 10.1016/j.compenvurbsys.2019.101425.

[8] Phelps, N.A., Sequel to Suburbia: Glimpses of America's Post-suburban Future, MIT Press: Cambridge, MA, 2015.

[9] Sassen, S., Global cities and developmentalist states: How to derail what could be an interesting debate: A response to Hill and Kim. Urban Studies, 38(13), pp. 2537-2540, 2001. DOI: 10.1080/00420980120094650.

[10] Ingersol, R., Sprawltown: Cercando la citttà in Periferia, Meltemi, 2004.

[11] Indovina, F., La città diffusa, Che cos'è e come si governa. 1999.

[12] Bonomi, A. \& Abruzzese, A., La città infinita, B. Mondadori, 2004. ISBN13:9788842496410.

[13] Garreau, J., Edge city: Life on the new frontier. American Demographics, 13(9), pp. 24-31, 1991.

[14] Phelps, N.A., Suburbs for nations? Some interdisciplinary connections on the suburban economy. Cities, 27(2), pp. 68-76, 2010.

[15] Young, D. \& Keil, R., Reconnecting the disconnected: The politics of infrastructure in the in-between city. Cities, 27(2), pp. 87-95, 2010.

[16] Gibelli, M.C., La dispersione urbana in Europa. I costi collettivi della città dispersa, eds R. Camagni, M.C. Gibelli \& P. Rigamonti, Alinea editrice: Florence, Italy, 2002. 
[17] Chetty, R., Hendren, N., Kline, P. \& Saez, E., Where is the land of opportunity? The geography of intergenerational mobility in the United States. National Bureau of Economic Research, 2014.

[18] Grazi, F., van den Bergh, J.C.J. \& van Ommeren, J., An empirical analysis of urban form, transport, and global warming. The Energy Journal, 29(4), pp. 97-122, 2008.

[19] Agrawal, A., Galasso, A. \& Oettl, A., Roads and innovation. The Review of Economics and Statistics, 99(3), pp. 417-434, 2017.

[20] Hoyt, H., Forces of urban centralization and decentralization. American Journal of Sociology, 46, pp. 843-852, 1941.

[21] Kenworty, J.R. \& Laube, F.B., Automobile dependence in cities: An international comparison of urban transport and land use patterns with implications for sustainability. Environmental Impact Assessment Review, 16, pp. 279-308, 1996.

[22] Dunphy, R., Moving Beyond Gridlock: Traffic and Development, Urban Land Institute: U.S., 1997.

[23] Di Mascio, P., Fusco, G., Grappasonni, G., Moretti, L. \& Ragnoli, A., Geometrical and functional criteria as a methodological approach to implement a new cycle path in an existing Urban Road Network: A Case study in Rome. Sustainability, 10(8), p. 2951, 2018.

[24] Cantisani, G., Durastanti, C. \& Moretti, L., Cyclists at roundabouts: Risk analysis and rational criteria for choosing safer layouts. Infrastructures, 6(3), p. 2021.

DOI: 10.3390/infrastructures6030034.

[25] Moretti, L., Moretti, M. \& Ricci, S., Upgrading of Florence public transport to incorporate new tramlines. [Riassetto del trasporto pubblico di Firenze a seguito dell'entrata in servizio di nuove linee di tram]. Ingegneria Ferroviaria, 72(7-8), pp. 569-584, 2017.

[26] Holtzclaw, J.W., Smart growth - As seen from tree air: Convenient neighbourhood, skip the car. Air \& Waste Management Association, 93rd Annual Meeting \& Exhibition, 2000.

[27] Sgarra, V., Di Mascio, P., Corazza, M.V. \& Musso, A., An application of ITS devices for powered two-wheelers safety analysis: The Rome case study. Advances in Transportation Studies, 33, pp. 85-96, 2014. DOI: 10.4399/97888548728997.

[28] Corazza, M.V., Musso, A., Finikopoulos, K. \& Sgarra, V., An analysis on health care costs due to accidents involving powered two wheelers to increase road safety. Transportation Research Procedia, 14, pp. 323-332, 2016.

DOI: 10.1016/j.trpro.2016.05.026.

[29] Trunzo, G., Moretti, L. \& D'Andrea, A., Life cycle analysis of road construction and use. Sustainability, 11(2), p. 377, 2019. DOI: 10.6092/1970-9870/22.

[30] Litman, T., Smart Congestion Relief-Comprehensive Analysis of Traffic Congestion Costs and Congestion Reduction Benefits, Victoria Transport Policy Institute, 2021. https://vtpi.org/cong_relief.pdf. Accessed on: 24 Mar. 2021.

[31] Litman, T., Land Use Impacts on Transport: How Land Use Factors Affect Travel Behavior, Victoria Transport Policy Institute, 2005.

[32] VTPI (Victoria Transport Policy Institute), TDM encyclopaedia, smart growth, more efficient land use management. 2005.

[33] Calthorpe, P. \& Associates, Design guidelines/final public review draft for Sacramento County planning community development department. 1990.

[34] Bernick, M. \& Cervero, R. (eds), Transit Villages in the 21st Century, McGraw-Hill: New York, 1997. 
[35] Still, T., Transit-oriented development: Reshaping America's metropolitan landscape. On Common Ground: REALTORS \& Smart Growth, National Association of Realtors: Washington, DC, pp. 44-47, 2002.

[36] Cervero, R., Ferrell, C. \& Murphy, S., Transit-oriented development and joint development in the United States: A literature review. TCRP Research Results Digest 52, National Research Council: Washington, DC, 2002.

[37] Calthorpe, P., The Next American Metropolis: Ecology, Community, and the American Dream, Princeton Architectural Press: Princeton, NJ, 1993.

DOI: 10.11113/ijbes.v5.n1.251.

[38] Forestieri, G. \& Álvarez de Buergo, M., Petrophysical-mechanical behavior of Grisolia stone for in the architectural heritage of southern Italy. Materiales de Construccion, 69(334), pp. 1-12, 2019. DOI: 10.3989/mc.2019.04118.

[39] Forestieri, G. \& Álvarez de Buergo, M., Relationships between petrophysical and mechanical properties of certain calcarenites used in building. Geotechnical and Geological Engineering, pp. 1-20, 2021. DOI: 10.1007/s10706-021-01810-2.

[40] Vanolo, A., Is there anybody out there? The place and role of citizens in tomorrow's smart cities. Futures, 82, pp. 26-36, 2016.

[41] Giffinger, R., Fertner, C., Kramar, H., Kalasek, R., Pichler-Milanović, N. \& Meijers, E., Smart cities-Ranking of European medium-sized cities. Final Report, Centre of Regional Science: Vienna, 2007.

[42] EC (European Commission), Europe 2020: A European Strategy for Smart, Sustainable and Inclusive Growth, EC: Brussels, 2010.

[43] Whitehead, M., The sustainable city: An obituary? On the future form and prospects of sustainable urbanism. The Future of Sustainable Cities: Critical Reflections, eds R. Flint \& M. Raco, The Policy Press: Chicago, pp. 29-46, 2012.

[44] Artmann, M., Kohler, M., Meinel, G., Gan, J. \& Ioja, J.C., How smart growth and green infrastructure can mutually support each other - A conceptual framework for compact and green cities. Ecological Indicators, 96(Part 2), pp. 10-22, 2019.

[45] Haaland, C. \& van den Bosch, C.K., Challenges and strategies for urban green-space planning in cities undergoing densification. A Review: Urban for Urban Greening, 14, pp. 760-771, 2015.

[46] Jansson, M., Green space in compact cities: The benefits and values of urban ecosystem services in planning. Nordic Journal of Architectural Research, 2, pp. 139160, 2014.

[47] Frank, L.D., Schmid, T.L., Sallis, J.F., Chapman, J. \& Saelens, B.E., Linking objectively measured physical activity with objectively measured urban form: Findings from SMARTRAQ. American Journal of Preventive Medicine, 28(2), pp. $117-125,2005$.

[48] Galster, G., Hanson, R., Ratcliffe, M.R., Wolman, H., Coleman, S. \& Freihage, J., Wrestling sprawl to the ground: Defining and measuring an elusive concept. Housing Policy Debate, 12, pp. 681-717, 2001. DOI: 10.1080/10511482.2001.9521426.

[49] Chinazzi, M. et al., The effect of travel restrictions on the spread of the 2019 novel coronavirus (COVID-19) outbreak. Science, 80(368), pp. 395-400, 2020.

DOI: $10.1126 /$ science.aba9757.

[50] Kraemer, M.U.G. et al., The effect of human mobility and control measures on the COVID-19 epidemic in China. Science, 80(368), pp. 493-497, 2020.

DOI: $10.1126 /$ science.abb4218. 
[51] TIC, The impact of COVID-19 on transport demand, modal choices, and sectoral energy consumption in Europe - External Publications - Publications - Fondazione Eni Enrico Mattei (FEEM). 2021. https://www.feem.it/en/publications/externalpublications/the-impact-of-covid-19-on-transport-demand-modal-choices-andsectoral-energy-consumption-in-europe/. Accessed on: 4 Apr. 2021.

[52] Muhammad, S., Long, X. \& Salman, M., COVID-19 pandemic and environmental pollution: A blessing in disguise? Science of the Total Environment, 728, p. 138820, 2020. DOI: $10.1016 /$ j.scitotenv.2020.138820.

[53] Moslem, S., Campisi, T., Szmelter-Jarosz, A., Duleba, S., Nahiduzzaman, K.M. \& Tesoriere, G., Best-worst method for modelling mobility choice after COVID-19: Evidence from Italy. Sustainability, 12, p. 6824, 2020. DOI: 10.3390/SU12176824.

[54] Corazza, M.V. \& Musso, A., Urban transport policies in the time of pandemic, and after: An ARDUOUS research agenda. Transport Policy, 103, pp. 31-44, 2021.

[55] Bieliński, T. \& Ważna, A., Electric scooter sharing and bike sharing user behaviour and characteristics. Sustainability, 12, p. 9640, 2020. DOI: 10.3390/su12229640.

[56] Forestieri, G. \& Galiano, G., Sustainable transport network for the urban rehabilitation of an old town in Southern Italy. WIT Transactions on the Built Environment, vol. 182, WIT Press: Southampton and Boston, pp. 229-239, 2019. DOI: 10.2495/UT180221.

[57] Forestieri, G., Marseglia, G. \& Galiano, G., Recovery and optimization of a former railway transport track. WIT Transactions on the Built Environment, vol. 186, WIT Press: Southampton and Boston, pp. 47-57, 2019. DOI: 10.2495/UT190051.

[58] Corazza, M.V., Di Mascio, P. \& Moretti, L., Management of sidewalk maintenance to improve walking comfort for senior citizens. WIT Transactions on the Built Environment, vol. 176, WIT Press: Southampton and Boston, pp. 195-206, 2018. DOI: $10.2495 / \mathrm{UT} 170171$.

[59] Di Mascio, P., D’Alessandro, D., Moretti, L. \& Corazza, M.V., Walking on the safe side: A methodology to assess pavements quality conditions for pedestrian. Transportation Research Procedia, 45, pp. 360-367, 2020.

DOI: $10.1016 /$ j.trpro.2020.03.027. 